This article is (C) Emerald Group Publishing and permission has been granted for this version to appear here (open.uct.ac.za). Emerald does not grant permission for this article to be further copied/distributed or hosted elsewhere without the express permission from Emerald Group Publishing Limited. DOI: 10.1108/S1479-3628(2013)0000009016

Collier-Reed, B., \& Ingerman, A. (2013). Phenomenography: From critical aspects to knowledge claim. In M. Tight \& J. Huisman (Eds.), International Perspectives on Higher Education Research (Vol. 9, pp. 243-260).

\title{
Phenomenography: From critical aspects to knowledge claim
}

\author{
Brandon Collier-Reed ${ }^{1}$ \& Åke Ingerman ${ }^{2}$ \\ ${ }^{1}$ Centre for Research in Engineering Education and Department of Mechanical Engineering, \\ University of Cape Town, South Africa \\ ${ }^{2}$ Department of Pedagogical, Curricular and Professional Studies, University of Gothenburg, \\ Sweden
}

\begin{abstract}
In this description of phenomenography, we take a functional view of the theoretical underpinnings that have traditionally been used to support its trustworthiness as a qualitative research approach. The chapter has two objectives, first to serve as an introduction for those considering embarking on research with a phenomenographic framing, and second to enable the recognition of the quality and scope of the knowledge claim inherent in phenomenographic outcomes.
\end{abstract}

\section{Considering phenomenographic research}

The phenomenographic tradition emerged as an alternative to studying learning from a quasicognitive-psychological framing with focus being directed towards understanding the relationship between a student ${ }^{1}$ and a phenomenon in the world. It strives to explore and describe the world from the students' perspective, and the ways in which it makes sense to them. A basic assumption is that the world makes sense to students, at least in the situations that phenomenography directs its interest toward. Phenomenography is fundamentally 'an approach to identifying, formulating, and tackling certain sorts of research questions' (Marton \& Booth, 1997, p.111) and is typically pedagogically focused. These research questions are varied and include such diverse higher education themes as, for example, the challenges for new academics in adopting student-centred approaches to teaching (Sadler, 2012), student science teachers' conceptions of sustainable development (Kilinc \& Aydin, 2011), the understanding of Lutheranism and its implications for religious education (Hella, 2008), and understanding geoscience as an academic discipline (Stokes, 2011). In each case, the researcher is not asking 'Why is this so?' but rather questions such as 'In what respect do these ways of understanding differ?'

In deciding whether phenomenography can help a researcher answer the question posed in their research, it is important to take care to frame the question appropriately. As the approach is directed towards understanding the relationship between a student and a phenomenon in the world, it is important that the phenomenon is one that is able to be clearly articulated and shared by those participating in the research. As the focus of the research is not on the phenomenon per se, but rather on describing how students may conceive of the phenomenon, a critical first step is the researcher ensuring that participants attend to the same phenomenon during the data collection process. This is often non-trivial as the nature of some phenomena is such that it is

\footnotetext{
${ }^{1}$ In this text, given its focus on higher education, we have elected to refer to 'students' as having agency in relation to a phenomenon in question. This is purely for convenience and does not imply that students have any special value as participants in research activities.
} 
challenging to ensure that participants describe their relationship with the same phenomenon as other participants.

The result developed through a phenomenographic analysis is a descriptive account of the range of different ways in which the phenomenon is conceived of by the participants. The richness of the result is manifested through the relationships in structure and meaning that are explicitly developed both within and between the emergent categories. In determining the appropriateness of using a phenomenographic approach for answering the question posed by the research in question, it is important to recognise that the outcome of an analysis is firmly located at the level of the collective and that attributing it to an individual student is methodologically inappropriate.

Having identified that the nature of a research question is such that the use of phenomenography is appropriate, we turn our attention to what it means for the outcome of research to be considered phenomenographic.

\section{The meaning of "phenomenographic"}

The term 'conception' ${ }^{2}$ is often used to refer to ways of making sense of a phenomenon in the world. It is evident that people, even in the same situation, make sense of specific phenomena in distinctly different ways. This is to be expected given differences in communication and action in relation to the phenomenon in question. Exploring and describing the nature of such a conception is most meaningfully undertaken in conjunction with describing other conceptions of the same phenomenon - in contrast with and in relation to one another. Conceptions can be thought of as making up the unit of analysis in phenomenography and refer to 'whole quantities of human-world relations' (Johansson, Marton, \& Svensson, 1985, p.249). However, conceptions are not visible 'but remain tacit, implicit, or assumed' (ibid, p.236). How then can phenomenography have conceptions as the object of research if they cannot be studied directly? Phenomenography takes the view that conceptions become visible when contrasted with one another since it is their constitution that manifests qualitative differences.

The outcome of a phenomenographic analysis is a collection of categories (often referred to as categories of description) that are qualitatively different from one another and are constituted from a number of critical aspects. These categories have both structure and meaning ${ }^{3}$ and are borne out of the relationship between students and a phenomenon. In relation to a particular phenomenon and a particular group of students, a researcher must distinguish fundamental differences in how these students make sense of their world. In the phenomenographic process it is important to identify and articulate such fundamental differences and to relegate to the background, during the analysis, the incidental differences. This implies the importance of being able to describe just what it is that is different from something else, i.e. in what respects A and B are different. It is critical aspects that help constitute these differences. These critical aspects manifest themselves as separate relationships between situations within how a

\footnotetext{
${ }^{2}$ It has been common practice in phenomenography to use the terms conceiving, conceptualising, understanding, experiencing, apprehending, and comprehending synonymously. As Marton and Pong (2005) argue, 'it is perfectly clear that "conceptualizing" is not identical with "experiencing"; ... The reason for using so many different synonyms is that although none of them corresponds completely to what we have in mind, they all do to a certain extent' (p.336). While the use of each is dictated by the object of research, we have largely adopted the use of 'conception' given its central place as the unit of analysis of phenomenographic research.

${ }^{3}$ In phenomenographic literature, the 'meaning' aspect associated with a category of description is sometimes referred to as its referential aspect.
} 
phenomenon is experienced. They are different from one another and can point to either aspects of structure or of meaning, unlike the qualitatively different nature of the categories where both structural and meaning elements together, and inseparably, describe their relationship. For example, in a study that investigated engineering students' conceptions of force (Johansson, Marton \& Svensson, 1985, also described in Marton \& Booth, 1997), it was determined that for these students, a Newtonian understanding of the concept of force was qualitatively different from an Aristotelian one. In other words, there is a qualitative difference between seeing that the net force on an object moving with constant speed is zero, or that a force in the direction of movement is necessary in order for the movement to continue. An educationally critical aspect associated with this qualitative difference concerns the shift from seeing force as causing a change in position (and thus related to velocity) to seeing force as causing a change in velocity (and thus related to acceleration).

Given the importance of the structural and meaning relationship between categories of description, it becomes apparent that referring to the outcome of a phenomenographic study simply in terms of the titles of the categories is fairly meaningless. It is in the relationship within and between these categories that the richness of the results is manifested. For example, the notion of 'deep versus surface approach to learning' is often spoken of in educational settings. Academics have a fairly distinct view of what they believe the differences between these two categories are, and the relevance of them to teaching and learning. However, the actual understanding of what these categories are meant to capture is lost unless one recognises the qualitative differences between these two as originally described by Marton and Säljö (Marton \& Säljö, 1976a, 1976b). Furthermore, to make use of this richness in one's current context, it is critical to explicitly recontextualise the original categories in an appropriate way. In a recent study by Hella (2008) on Finnish students' understanding of Lutheranism and its implications for religious education, she presents a description of the categories as follows:

'In Category 1, Lutheranism is discerned as a religion in terms of distinguishing between religious and non-religious phenomena. ... In Category 3, the distinction between living as a 'true' or 'real' believer, and living ... as a nominal Christian is based on the external perception of consistency between knowledge of Lutheran beliefs and a practical way of living' (p 254).

Simply referring to the categories as titled ('Lutheranism as a religion' and 'Lutheranism as nominal Christians and real believers' respectively) does not adequately reflect in itself the qualitative differences inherent in the categories let alone the critical aspects embedded therein (nor does our limited quote and the reader would need to refer to the original article for a full understanding thereof). In another study Paakkari et al. (2011) specifically highlight the educationally critical aspects that helped them constitute their categories of description. 'The nature of reflection' is one such critical aspect (constituted as a theme of expanding awareness (Åkerlind, 2005)) and is presented either as descriptive reflection, critical reflection, ethical reflection, collective reflection, or not present. These critical aspects then helped constitute the structure and meaning of the categories of description. Importantly - and as discussed earlier - 'reflection' is only one aspect that helps constitute the categories and does not appear in the descriptive title associated with each. 


\section{Phenomenography as a research approach}

In reply to the question as to whether phenomenography is a method or a theory, the answer has often been that phenomenography is an approach including elements of both method and theory. The historical development of the phenomenographic tradition has shifted its attention between practical concerns, the theoretical underpinning, and the development of theoretical ideas of how learning comes about. Variation theory (Marton \& Tsui, 2004) [\& REF to other chapter] is one of the more recently developed ideas and focuses on the pedagogical utilization of phenomenography in the design of educational activities. The original studies (Marton, Dahlgren, Svensson, \& Säljö, 1977; Marton \& Säljö, 1976a, 1976b) developed as a reaction to the dominant quasi-cognitive psychological framing of the time, starting from "simple" ideas of what was researched. It focused primarily on why some people understand some things differently to others, and the core of that difference. They took a practical approach to generating particular kinds of data and searching for particular kinds of patterns. The outcome of these early studies had a significant impact, particularly in higher education. Inevitably, there emerged questions as to how the studies were underpinned. Responses (eg. Marton, 1981), which substantiated phenomenography as a robust and distinct approach, were followed by new questions, as well as by new ways of addressing the central concerns in the now established tradition. Specifically, there emerged a theoretical reconstitution of the work in terms of learning (as synthesised by Marton \& Booth (1997)). We will now turn our attention to describing the process of conducting a phenomenographic study.

\section{Embarking on a phenomenographic study}

A typical phenomenographic study has students perform a task, engage in some activity, or targets students from a specific context such as a course or those enrolled in a particular programme or discipline - ostensibly to ensure that it is a shared phenomenon that is in focus. Thereafter the students would report on it and describe how they had gone about this task or activity. Marton and Booth (1997) describe how initially 'the phenomenon that the [student] is being asked to handle is ... brought to awareness by the interviewer in an open and concrete form. [Thereafter, the student] herself has to discern the phenomenon and distinguish it from the situation as a whole' (p.130). It is helping students to reach this state of meta-awareness that needs to be central to a phenomenographic data collection strategy. Depending on the phenomenon under investigation, a researcher can help ensure a shared experience of the phenomenon in different ways. In some instances, it is enough to have students each read the same text (Marton \& Säljö, 1976a, 1976b), while in other instances other approaches have to be adopted such as Collier-Reed (2006) using photographs taken by students of the phenomenon in question.

An analysis of published phenomenographic studies shows that data are collected in predominantly two ways - either through an interview or through text written by the student in response to a specific question. Other methods have been used, such as reviewing film footage of one-year-old toddlers' experience of their first three months in nursery school (Lindahl, 1995, also discussed in Marton \& Booth (1997)) but are less common. As the interview is the most common method of data collection, this approach will form the focus of the discussion to follow. The typical phenomenographic interview is of a semi-structured nature with only a few key questions predetermined. This is in contrast to the archetypal qualitative interview where a detailed framework of the interview is developed beforehand. That is not to say that the phenomenographic interview is without focus. The object of study is held central to the interviewer's focus at all times and guides the interview situation. The majority of the interview 
is thus centred around following up and exploring different aspects of the interviewee's reflections on the theme as thoroughly as possible.

The phenomenographic interview as a legitimate way of exploring a person's relationship with a phenomenon is one aspect that has been the target of critique, no more so than by Säljö (1996, 1997). Central to Säljö's concern is his view that the phenomenographic interview is in essence simply a social construction. He cautions that researchers need to be careful about what they decide a conversation is indicative of, especially considering the weight phenomenographers place on the interview conversation. Säljö suggests that phenomenographers do not recognise the 'primacy of talk' (Säljö, 1996, p.20) in an interview situation. On the other hand, recognising the primacy of the collective reflection by students on different ways of making sense of a phenomenon suggests that the phenomenographic data collection in the form of interviews should not be caught in the paradox of separate practices in interviews and other situations. However, Säljö's critique is important to consider in the design of the interview, as it will impact on the quality of the data collected.

The methodological underpinning of phenomenography posits that the data collected be representative of the relationship between a student and a phenomenon in the world as described by that student. What then makes a particular method appropriate as part of a phenomenographic research approach? It is one that has a data collection strategy that facilitates a student reflecting on their relationship with that phenomenon. This form of reflection is not necessarily something that happens spontaneously, but enabling it is the key to an appropriate method of data collection. The interview should allow aspects of a student's relationship with a phenomenon to be thematised where it may, without the interview, not have been. Critical to achieving this is the researcher and student establishing a 'shared definition' (Bowden, 1996, p.58) of the phenomenon under discussion. It should be recognised that the interview conversation is 'jointly constituted by the interviewer and the [student]' (Marton, 1994, p.4427) and is thematised through a 'conversation between two partners about a theme of mutual interest' (Kvale, 1996, p.125). Säljö (1996, p.23) has referred to this 'theme' as a shared topic of discourse.

\section{Characteristics of the research participants}

A critical question relating to phenomenographic studies is who to interview. The focus of a phenomenographic analysis is on qualitative differences and purposive sampling is a technique that allows 'critical cases' (Cohen, Manion, \& Morrison, 2000, p.103) to be selected based on the judgement of the researcher. Including these critical cases in the purposively selected sample will thus give the best opportunity of manifesting the full extent of the various ways students have of making sense of a phenomenon. In determining the students most likely to provide this variation, consideration is not necessarily given to being inclusive of gender or particular cultural groups as may be central to many other methods. A researcher applies his/her mind to selecting critical cases without regard to what are, in a phenomenographic sense, nominally artificial distinctions.

A further issue relating the characteristics of the phenomenographic sample is how many people to interview. Phenomenographic data analysis does not entail 'keeping score' of fragments of the way students make sense of a phenomenon as they are placed in predetermined categories as may be the case in content analysis. Before a phenomenographic analysis takes place, there is no way of knowing the extent of the variation that has been captured during the interviews. Trigwell (2000, p.66) argues that between fifteen and twenty people is the ideal number to 
interview. He continues that 'ten to fifteen would be the minimum to create a reasonable chance of finding variation in the range' (ibid).

An aspect of a phenomenographic analysis, which has been criticised by some, is that it is possible for only a single interview to contribute to the constitution of a category. An important question to consider is what would have happened had this student not been amongst those interviewed. The answer to this involves a number of issues. The content of an interview is a conversation constituted between the researcher and the student being interviewed. During the interview, the student's description of their relationship with a phenomenon is not necessarily constant throughout the interview. It may vary, and possibly even change, as aspects are brought into focus and become figural (while others move to the margin) during the interview conversation. As a result, even though a particular student is one of those interviewed, there is no guarantee that during the conversation they will express what may turn out to singularly constitute a category. Just because it appears as though a category may have been constituted by an individual student, this is not so. It is constituted in terms of the relationship between that conception of the phenomenon in the context of all the other conceptions of that phenomenon. The best chance of ensuring the complete variation represented in the categories remains to sensibly select the students in the study to ensure as much variation as possible. It is the collective conceptions of the participants that is analysed. An individual is in this sense simply a contributor to this collective.

Although phenomenographers may use a number of different methods of analysis (Bowden \& Walsh, 2000; Walsh, 2000), they share the same underlying philosophy. Researchers (cf. Åkerlind, 2005) have gone as far as to compare the various approaches leading researchers have used to perform their phenomenographic analyses. The following is not necessarily a summary presentation of these different approaches, but rather an argument for one approach that can be adopted.

\section{Fragments of conceptions?}

Since a phenomenographic analysis does not have the same focus on linguistic elements as a methodological approach such as discourse analysis, it is not necessary to transcribe every tonal inflection or pause in speech. What is important is that the 'spoken word' is transcribed as accurately as possible as it forms the basis for the analysis to follow. Thus, with due recognition given to Kvale's (1996, p.165) concerns that the oral language of an interview is decontextualized into the written word, the transcripts need to accurately capture how a person has reflected over their experience of a phenomenon during the interview.

After the interview conversations have been transcribed, there is a difference in method amongst researchers about what the next step entails. In the classic formulation of the phenomenographic method, Marton $(1986,1994)$ suggests first selecting from the transcripts those sections where the students have focussed on reflecting over their experience of the phenomenon in question. The next step is literally to cut out excerpts that relate to the experience of the same phenomenon and place these in a pile on a table in what he refers to as a 'pool of meaning' (Marton, 1994, p.4428). This pool of meaning is essentially a collection of fragments from all the interviews that refer to an experience of the phenomenon in question and forms the starting point for further analysis. Prosser (2000) takes a different view and indicates that he deals with transcripts as a whole. However, he argues that the only workable course of action for dealing with the process of analysis is to divide the transcripts into what he calls 'related parts' (ibid, p.45) and then analyse these parts in relation to each other and in 
relation to the categories constituted. Bowden (2000) on the other hand 'prefer[s] to deal with the whole transcript all of the time' (p.12). He looks at 'any particular utterance' (ibid) in the context of what was said in the interview as a whole and argues that placing excerpts in and working from a pool of meaning runs the risk of complete decontextualisation from the original transcript. However, Marton (1994) counters this argument by specifically stating the requirement during analysis to 'make sense of particular expressions in terms of the collective as well as of the individual context' (p.4428). Even so, this is one area where care during analysis of data in the pool of meaning is required to ensure that the relevant contexts from which the excerpts come are held in the researcher's focus.

During an interview, the researcher jointly constructs the conversation with the student and guides the interview keeping the object of research in mind at all times. The student's reflection on their relationship with the phenomenon in question can (and often does) change as various aspects are brought into focus and others recede to the periphery of their awareness at that time. This scenario complicates considering an interview as a whole as this approach has difficulty dealing with the different expressions of relationships with a phenomenon. The process of selecting excerpts from transcripts relating to specific phenomena, and considering these together, largely overcomes this issue.

The first step in the process towards constituting an outcome space is to populate the pool of meaning with the collection of fragments from all the interviews that refer to an experience of the phenomenon in question (assuming a Martonian constitution of the pool of meaning). This is achieved by carefully reading the transcripts and looking for meaning units in the text that relate to this phenomenon. These sections of text could be a single answer to a question or part of a longer conversation. The key here is that the student should be focussing on a single aspect of the phenomenon for the duration of the meaning unit. Once the individual meaning units have been identified across all the interviews, the interviews are deconstructed and only the individual meaning units retained. This is achieved by literally taking out the appropriate sections of text and discarding the irrelevant text. These meaning units are 'placed' in the pool of meaning that then contains all the possible relationships with the phenomenon in question. The individuals interviewed have thus provided fragments of the ways of relating to the phenomenon to this pool and the assumption is that, at a collective level, this would represent the variation in ways to which the phenomenon is related. The data is thus homogenised by removing unimportant differences such as the terminology used during the interviews and the integration and generalisation of important similarities (Dahlgren, 1997).

Once the pool of meaning is populated with these 'meaning units of experience', Marton (1986) has described in detail a process for the next stage in the constitution of the categories of description:

The selected quotes make up the data pool which forms the basis for the next and crucial step in the analysis. The researcher's attention has now shifted from the individual subjects (i.e., from the interviews from which the quotes were abstracted) to the meaning embedded [in] the quotes themselves. The boundaries separating individuals are abandoned and interest is focused on the "pool of meanings" discovered in the data. Thus, each quote has two contexts in relation to which it has been interpreted: first, the interview from which it was taken, and second, the "pool of meanings" to which it belongs. The interpretation is an interactive procedure which reverberates between these two contexts. A step-bystep differentiation is made within the pool of meanings. As a result of the 
interpretive work, utterances are brought together into categories on the basis of their similarities. Categories are differentiated from one another in terms of their differences. In concrete terms, the process looks like this: quotes are sorted into piles, borderline cases are examined, and eventually the criterion attributes for each group are made explicit. In this way, the groups of quotes are arranged and rearranged, are narrowed into categories, and finally are defined in terms of core meanings, on the one hand, and borderline cases on the other. Each category is illustrated by quotes from the data.... As the meanings of categories begin to form, those meanings determine which quotes should be included and which should be excluded from specific categories. (p.43)

In the description above, little detail is provided about how 'utterances are brought together into categories on the basis of their similarities' and how 'categories are differentiated from one another in terms of their differences'. One approach for constituting the categories, drawing in part on Akerlind's (2003) notion of 'themes of expanding awareness', is as follows. From within the pool of meaning, meaning units are read in the context of all those that have come before and in the context of the interviews from where they have been derived. Each meaning unit informs and helps delineate the others. Critical aspects are identified and these help to recognise themes that run through the data. These themes are used to help constitute the logical relationships both within and between the categories as they develop. The analysis alternates between the categories as they are being constituted, the identification of critical aspects, and the themes looking to substantiate, contradict or revise the relationships that are emerging. The important issue here is that these themes point to those key aspects that help delineate the different categories. The constitution of themes helps give structure and meaning to the categories, both within and between them. These themes emerge through an iterative process that involves reading and rereading quotes from the transcripts, looking for structure, meaning and order as the themes are constituted and reconstituted. The final ordering of the constitutive elements of the categories is 'based on both logical and empirical evidence' (Åkerlind, 2003, p.91).

The categories of description constituted through this analysis make up the 'outcome space' 'the complex of categories of description comprising distinct groupings of aspects of the phenomenon and the relationships between them' (Marton \& Booth, 1997, p.125). Central to this outcome space is that the categories will be logically related. Typically, this may be manifested by each successive category being a more complex way of understanding the relationship with the phenomenon under investigation. This logical relationship may be articulated in terms of the critical aspects. Specifically, if it is possible to identify critical aspects connecting all categories consecutively, that in itself embodies the logical relationships implied in claiming that the results are "phenomenographic".

The outcome space is thus a robustly constituted set of logically related categories comprising distinct groupings of aspects of the phenomenon. These categories are qualitatively different from each other and represent the variation in the way of relating to the phenomenon. The categories are differentiated from one another by the critical aspects in the ways of relating to a phenomenon that they each contain. The nature of the categories are important and Marton and Booth (1997, p.125) indicate that categories need to fulfil three criteria for them to be phenomenographic. The first is the requirement for the categories to be logically related. The second requirement is that the minimum number of categories that fully describe the relationship with the phenomenon must be used, and finally that each category must completely 
describe a distinctly different aspect of the relationship with the phenomenon, i.e. each category must be qualitatively different from the others.

\section{Towards a knowledge claim}

So far, we have taken for granted that the outcome of a phenomenographic study is to be valued on its own terms. However, we believe that in each case it is an important part of the process to specifically consider and reflect on what the knowledge claim resulting from the study may be. In addition to the theoretical underpinnings of the practical approach discussed earlier, there are several other theoretical ideas that could contribute to enhancing the quality and legitimacy of a knowledge claim. Some of the more important of these are discussed below, focusing firstly on those particularly related to pedagogy and then moving to more general considerations.

The set of categories resulting from a study is a statement of the ways of conceptualising the phenomenon in question as related to the empirical context. However, phenomenography has from the outset had a pedagogical focus and attempted to add value to pedagogical practice. On the basis of a large number of specific studies, Marton and Booth (1997) mapped out a phenomenologically inspired model of learning as an expanding differentiation of distinctive features of different phenomena. This model, in accordance with phenomenography's focus on the qualitative differences of conceptions, features learning as the coming to see the distinctive qualities of powerful ways of seeing different phenomena. The core of the model suggests that the recognition of the critical aspects is a necessary condition for learning about the phenomenon. Variation, which brings the critical aspect(s) to the fore, is the mechanism through which this may happen. Teaching that supports variation of relevant aspects and distinguishes it from irrelevant aspects may support this process. The systematic operationalization of supporting relevant variation is referred to as variation theory (Marton \& Tsui, 2004). This model of learning gives substance to how the phenomenographic outcome is by theoretical implication also a knowledge claim with respect to the pedagogical issues related to the research question, both with respect to its context and the phenomenon focused upon.

In the early days of phenomenography, most researchers leaned on a quasi-positivistic framing of the constitution of the outcome space, claiming that through phenomenography 'different layers of the perceived world can be revealed' (Marton, 1981, p.190). This notwithstanding, it has been clear all along that phenomenography focuses on the human-world relation, and not phenomena in the world as such. Nevertheless this has resulted, for example, in the use of interjudge reliability (cf. Johansson, et al., 1985; Marton, 1996; Säljö, 1988) as demonstrative of how rigour of the research process can be assured. Later work has largely abandoned this kind of measure, recognising the argument of Sandberg (1997, p.207) who indicates that interjudge reliability produces theoretical and methodological inconsistency, and instead have moved towards seeing the set of categories as a researcher-based construction for the purpose of understanding the empirical data collected. Having raised this about the ontological status of the categories, the knowledge claim of the categories is not restricted to being only a sensemaking tool for the original empirical data in the original research process. The categories and critical aspects should also have qualities in terms of showing potential for teachers (and researchers) to make sense of how students manifest (talk about, etc) their conceptions in different contexts. This then offers possibilities for identifying the constitution of the students' sensemaking - with the categories/critical aspects also taking the form of a culturalpedagogical tool for facilitating learning about this specific phenomenon. 
The establishment of a distinct knowledge claim from a phenomenographic study, whether it is located in educational research or in relevant professional practice, fundamentally concerns the communicability of the categories and critical aspects. Communicability includes expressing the rationality of categories and critical aspects in terms of their logic - internally as well as externally - richness, and relationship to the original data, as well as answering to their relationship to the overall research purpose. Furthermore, it is also to present the results and conclusions of a study to the research/professional community in an open way that enables the study as a whole to be scrutinised and critiqued. The primary purpose of doing so is to encourage and facilitate the research community recognising and judging for themselves the communicative credibility of the results in a holistic sense (Booth, 1992; Collier-Reed, Ingerman, \& Berglund, 2009; Kvale, 1996). Furthermore, communicability also concerns the quality of the relationship between the original researcher and other researchers/professionals. It relates to the requirement of the researcher to be able to 'argue persuasively for the particular interpretation that they have proposed' (Åkerlind, 2005, p.330). Pushing the boundaries of what may typically have been considered reasonable; there should be an analysis of how the study may be further interpreted in other contexts as well as establishing a dialogical and embodied relationship going beyond the claims about the study done as it exists in published form. Given the context of many higher education studies where the researcher may also be a professional educator or have a distinct relationship to such a community, the effective substance of the knowledge claim within that community may also be based on further aspects and elements over and above what is possible to include in the formal writing of scientific reports.

The core nature of the knowledge claim is determined by the epistemological status of the categories. In phenomenography this primarily depends on the relationship between the categories and the conceptions, as well as the level of established correspondence between the practical implementation and the theoretical idea of the object of research - the phenomenon in its empirical and ideal form. For example, the idea of the phenomenon that is to be focused on must correspond to the manifestation of this phenomenon given in the empirical situation through interview questions and/or other aspects of the empirical design. The epistemological status of a set of categories is thus that of capturing a connected set of conceptions which adhere to the characteristics of phenomenographic outcomes, such as logical relationships and being of the same phenomenon.

Finally, we would like to raise the issue of how the knowledge claim in phenomenographic work is dependent on the original context. Critique has been raised of the danger (and at times strength) of the decontextualisation inherent in the transformation from an 'untarnished' pool of meaning and interview data to stripped descriptions on an abstract level of more or less generic categories (for example, from the phenomenological perspective, see Ashworth \& Lucas, 2000). This is at the same time a recontextualisation of the original individual statements into the context of all the statements in the pool of meaning and into a scholarly context of the phenomenographic research outcome as a whole. We recognise Säljö’s concern (1994, p. 77) that 'the recontextualisation does not seem to work on all occasions, since the end product does not always generate food for thought or clues to action'. This suggests the necessity of not only good conduct in phenomenographic work, but also careful consideration of the research intent and design or you will likely be asked the "So what?" question - inevitably raised by some colleagues and other professionals.

We have presented the most important considerations related to the scope and stability of the knowledge claim that can be made on the basis of a well-designed and conducted 
phenomenographic study. In the final section we suggest how it is possible to move beyond the phenomenographic research process in a way that adds value to the original knowledge claim.

\section{Beyond phenomenographic results}

Phenomenographic results may be used in a number of ways, some of them 'nonphenomenographical'. An illustrative case is some of the early original work on approaches to learning, which had a large impact, but has been given a diverse array of interpretations over the years, both valuable and problematic (c.f. discussion by Haggis (2003) on the impact of approaches to learning on the higher education field). This may be out of the hands of the original researcher, but nothing precludes him/her from facilitating uses that are true to the intended research purpose. This may include university teachers researching their own practice, focused projects of curriculum development, or basic research on general aspects of learning and teaching in higher education. In particular, the phenomenographic tradition is fond of providing leverage for a wide range of pedagogical innovation, whether specifically located in the context of the original research, reinterpreted in other contexts or simply generic in nature. Being put to such use, phenomenography as a research approach continues to be of importance to the research and professional higher education communities.

\section{References}

Åkerlind, G. S. (2003). Growing and developing as an academic. Implications for academic development, academia and academic work. PhD thesis, University of Sydney, Australia.

Åkerlind, G. S. (2005). Variation and commonality in phenomenographic research methods. Higher Education Research and Development, 24(4), 321-334.

Ashworth, P., \& Lucas, U. (2000). Achieving empathy and engagement: A practical approach to the design, conduct and reporting of phenomenographic research. Studies in Higher Education, 25(3), 295-308.

Booth, S. (1992). Learning to program: A phenomenographic perspective. (Vol. 89): University of Gothenburg.

Bowden, J. A. (1996). Phenomenographic research - Some methodological issues Reflections on phenomenography - Toward a methodology? (Vol. 109, pp. 49-66): University of Gothenburg.

Bowden, J. A. (2000). The nature of phenomenographic research. In J. A. Bowden \& E. Walsh (Eds.), Phenomenography (pp. 1-18). Melbourne: RMIT University Press.

Bowden, J. A., \& Walsh, E. (2000). Phenomenography. Melbourne: RMIT University Press.

Cohen, L., Manion, L., \& Morrison, K. (2000). Research methods in education (5th ed.). London ; New York: RoutledgeFalmer.

Collier-Reed, B. I. (2006). Pupils' experiences of technology: Exploring dimensions of technological literacy. PhD thesis. University of Cape Town. Cape Town.

Collier-Reed, B. I., Ingerman, A., \& Berglund, A. (2009). Reflections on trustworthiness in phenomenographic research: Recognising purpose, context and change in the process of research. Education as Change, 13(2), 339-355.

Dahlgren, L. (1997). Outcomes of learning. In F. Marton, D. Hounsell \& N. Entwistle (Eds.), The experience of learning (2 ed., pp. 19-35). Edinburgh: Scottish Academic Press.

Haggis, T. (2003). Constructing images of ourselves? A critical investigation into'approaches to learning'research in higher education. British Educational Research Journal, 29(1), 89-104. 
Hella, E. (2008). Variation in Finnish students' understanding of Lutheranism and its implications for religious education: a phenomenographic study. British Journal of Religious Education, 30(3), 247-257. doi: 10.1080/01416200802170185

Johansson, B., Marton, F., \& Svensson, L. (1985). An approach to describing learning as a change between qualitatively different conceptions. In L. Pines \& T. West (Eds.), Cognitive structure and conceptual change (pp. 233-257). New York: Academic Press.

Kilinc, A., \& Aydin, A. (2011). Turkish Student Science Teachers' Conceptions of Sustainable Development: A phenomenography. International Journal of Science Education, 1-22. doi: 10.1080/09500693.2011.574822

Kvale, S. (1996). Interviews: An introduction to qualitative research interviewing: Sage Publications.

Lindahl, M. (1995). Inlärning och erfarande: ettåringars möte med förskolans värld [Experience and learning: one-year old children's encounter with the world of preschool]. Göteborg: Acta Universitatis Gothoburgensis.

Marton, F. (1981). Phenomenography - Describing conceptions of the world around us. Instructional Science, 10(2), 177-200.

Marton, F. (1986). Phenomenography - A research approach to investigating different understandings of reality. Journal of Thought, 21, 28-49.

Marton, F. (1994). Phenomenography. In T. Husén \& T. N. Postlethwaite (Eds.), The international encyclopedia of education (2nd ed., pp. 4424-4429). Oxford, England: Elsevier Science.

Marton, F. (1996). Cognosco ergo sum - Reflections on reflections. In G. Dall'Alba \& B. Hasselgren (Eds.), Reflections on phenomenography - Toward a methodology? (Vol. 109, pp. 163-187): University of Gothenburg.

Marton, F., \& Booth, S. (1997). Learning and awareness. New Jersey: Lawrence Erlbaum Associates.

Marton, F., Dahlgren, L., Svensson, L., \& Säljö, R. (1977). Learning and conception of the world around us. Stockholm: Almquist \& Wiksell.

Marton, F., \& Pong, W. Y. (2005). On the unit of description in phenomenography. Higher Education Research \& Development, 24(4), 335-348.

Marton, F., \& Säljö, R. (1976a). On qualitative differences in learning I - Outcome and process. British Journal of Educational Psychology, 46, 4-11.

Marton, F., \& Säljö, R. (1976b). On qualitative differences in learning II - Outcome as a function of the learner's conception of the task. British Journal of Educational Psychology, 46, 115-127.

Marton, F., \& Tsui, A. (2004). Classroom discourse and the space of learning. Mahwah, N.J.: L. Erlbaum Associates.

Paakkari, L., Tynjälä, P., \& Kannas, L. (2011). Critical aspects of student teachers' conceptions of learning. Learning and Instruction, 21(6), 705-714. doi: 10.1016/j.learninstruc.2011.03.003

Prosser, M. (2000). Using phenomenographic research methodology in the context of research in teaching and learning. In J. A. Bowden \& E. Walsh (Eds.), Phenomenography (pp. 34-46). Melbourne: RMIT University Press.

Sadler, I. (2012). The challenges for new academics in adopting student-centred approaches to teaching. Studies in Higher Education, 37(6), 731-745

Säljö, R. (1988). Learning in educational settings: Methods of inquiry. In P. Ramsden (Ed.), Improving learning: New perspectives (pp. 33-48). London: Kogan Page.

Säljö, R. (1994) Minding action. Conceiving of the world versus participating cultural practices. Nordisk pedagogik, 14(2), 71-80. 
Säljö, R. (1996). Minding action - Conceiving of the world versus participating in cultural practices. In G. Dall'alba \& B. Hasselgren (Eds.), Reflections on phenomenography (pp. 19-33). Goteborg: Acta Universitatis Gothenburgensis

Säljö, R. (1997). Talk as data and practice - a critical look at phenomenographic inquiry and the appeal to experience. Higher Education Research \& Development, 16(2), 173-190.

Sandberg, J. (1997). Are phenomenographic results reliable? Higher Education Research \& Development, 16(2), 203-212.

Stokes, A. (2011). A phenomenographic approach to investigating students' conceptions of geoscience as an academic discipline. Geological Society of America Special Papers, 474, 23-35.

Trigwell, K. (2000). A phenomenographic interview on phenomenography. In J. A. Bowden \& E. Walsh (Eds.), Phenomenography (pp. 62-82). Melbourne: RMIT University Press.

Walsh, E. (2000). Phenomenographic analysis of interview transcripts. In J. A. Bowden \& E. Walsh (Eds.), Phenomenography (pp. 19-33). Melbourne: RMIT University Press. 